\title{
Toward a better theoretical and practical understanding of field players' decision-making in handball: A systematic review
}

\author{
Guillaume Bonnet ${ }^{1,2, *}$, a , Thierry Debanne ${ }^{3}$, and Guillaume Laffaye ${ }^{1,2,4}$ \\ ${ }^{1}$ CIAMS Univ. Paris-Sud - Université Paris-Saclay, 91405 Orsay Cedex, France \\ 2 CIAMS, Université d'Orléans, 45067 Orléans, France \\ ${ }^{3}$ UR LIRTES, Université Paris-Est Créteil Val-de-Marne, Bât. La Pyramide, 94009 Créteil Cedex, France \\ ${ }^{4}$ Research Center for Sports Science, South Ural State University, Chelyabinsk, Russian Federation
}

Received 19 May 2019, Accepted 2 July 2020

\begin{abstract}
The aim of this review is to summarize current literature about decision-making in handball in order to identify potential gaps in the cognitive domain, and to propose directions for future research. Studies used various methods but rarely specified the theoretical framework. Two theoretical approaches are commonly used to study the decision-making in team sports. The cognitive approach was used in two thirds of the studies reported in this review. It focuses on skills used by a player to respond to different stimuli often in a non-specific context. These skills include attention, memory and perception. As expected, expert players tend to perform better in these cognitive tests compared to novices, especially when the task's complexity is high. In contrary, the naturalistic approach studies the way the player analyzes a real and experienced situation. The studies look first at the generation of options, for which expert players appear superior. Second, they assess team cognition which concerns the way a decision is integrated into a collective plan. In this paper, we've described some practical applications and highlighted the limitations and complementarity of these two approaches to study the importance of expertise in decision-making.
\end{abstract}

Key words: cognitive skills, perception, expertise, cognitive approach, naturalistic decision making

Résumé - Vers une meilleure compréhension théorique et pratique de la prise de décision des joueurs de champ au handball : une revue systématique. Le but de cette revue est de résumer les études actuelles traitant de l'activité décisionnelle au handball, d'identifier les manques potentiels de la recherche en sciences cognitives, et de proposer des orientations pour de futures recherches. Ces études ont utilisé différentes méthodes mais ont rarement précisé le modèle théorique utilisé. Deux approches théoriques permettent d'étudier l'activité décisionnelle en sports collectifs. L'approche cognitive représente deux tiers des études trouvées. Elle s'intéresse aux compétences utilisées par un joueur face à différents stimuli dans un contexte souvent non spécifique. Ces compétences incluent l'attention, la mémoire et la perception. Les joueurs experts apparaissent meilleurs que les novices, notamment lorsque la complexité de la tâche est élevée. En revanche, l'approche naturaliste étudie la façon dont le joueur analyse une situation réelle et expérimentée. Les études de cette approche s'intéressent tout d'abord à la génération d'options, dans laquelle les experts apparaissent supérieurs aux novices. Ensuite, ces études évaluent la cognition d'équipe qui concerne la façon dont les décisions sont prises dans le cadre d'un plan collectif. Nous avons décrit dans cette revue plusieurs applications pratiques et exposé les limites et la complémentarité de ces 2 approches pour étudier le lien entre expertise et activité décisionnelle.

Mots clés : capacités cognitives, perception, expertise, approche cognitive, prise de décision naturaliste

\footnotetext{
*Corresponding author: guillaume. bonnet@u-psud.fr ${ }^{\text {a} P r e s e n t ~ a d d r e s s: ~ L a b o r a t o i r e ~ C I A M S, ~ U n i v e r s i t e ́ ~ P a r i s ~ S u d, ~ B a ̂ t ~}$ 335, 91405 Cedex, France.
} 


\section{Introduction}

Handball $^{1}$ is an invasion and collision team sport with intermittent efforts and high intensity actions, with the objective to score more goals than the opposing team (Karcher \& Buchheit, 2014). Handball players have to quickly decide on the appropriate action, taking into account various parameters and with a certain degree of uncertainty. Over the past thirty years, several authors have studied decision-making in handball (Johnson \& Raab, 2003; Schapschröer, Baker, \& Schorer, 2016a, Schapschröer, Baker, \& Schorer, 2016b; Tenenbaum, Yuval, Elbaz, Bar-Eli, \& Weinberg, 1993). They focused primarily on perceptive aspects. They demonstrated that experts perform better in decision-making tasks, as they are better at analysis visual cues and other parameters influencing decision-making. However, no systematic review has been done on decision-making in handball. The aim of this paper is to summarize the current literature in this field and to propose directions for future research.

In handball, decision-making can be studied in different actors such as players, coaches or referees. Obviously, the type of decisions they must make is different because of their role and their position in or off the field. Whereas coaches must manage the players and make strategic decisions for their team (Debanne \& Chauvin, 2014), referees must have to make disciplinary decisions (Souchon, Cabagno, Traclet, Trouilloud, \& Maio, 2009). Similarly, the activity of field players is very different from that of goalkeepers. The decision-making of the field player is more complex because it involves their activity with or without the ball and in offensive or defensive phases. Moreover, they have to consider the balance of the power between themselves and their direct opponent: can they outrun them for example. In this study, we focused solely on decision making of field players.

\section{Approaches to study decision-making in team sports}

Researchers in cognitive ergonomics (Kobus, Proctor, \& Holste, 2001) and sports sciences (Bossard \& Kermarrec, 2011) agree that it exists two approaches to study decision-making processes. The cognitive one was the first to be developed and does not take into account the context of a decision. This approach focuses on micro-cognition, defined as the study of separate units of cognition (Klein, Klein, \& Klein, 2000). In contrary, the naturalistic approach studies the way a player analyzes a situation in a real context, taking into account its complexity. This

\footnotetext{
1 "Handball is a team sport played by two male or female teams consisting of seven players ( 6 fielders and 1 goalie) each. The players are allowed to handle and throw the ball using their hands, but they must not touch the ball with their feet" (except the goalkeepers who may stop the ball with any part of their body) (EHF).
}

approach focuses on macro-cognition (Klein et al., 2000), defined as the description of complex cognitive functions performed in a natural environment.

\section{The cognitive approach}

\section{Presentation}

The cognitive approach examines the information processing. It studies the processes and specific skills used by a player exposed to different stimuli to assess the situation and make a decision (Lex, Essig, Knoblauch, \& Schack, 2015). In this approach, the athlete is considered a rational and omniscient actor who assesses different possibilities to maximize their own behaviour (Macquet \& Fleurance, 2007). This method evaluates three main parameters: 1) the strategies to collect information in the environment, 2) the organization of the knowledge mobilized by the player and 3) the memory processes implicated (Bossard \& Kermarrec, 2011). These analyses are quantitative and performed using implicit methods, explicit methods or perceptive tasks. The explicit methods use simple questions, and verbalizations (McPherson \& Vickers, 2004). The implicit methods use recall tasks and recognition tasks, in which the subjects must find the correct objects or localizations (McMorris \& Beazeley, 1997). Studies on visual perception use occlusion methods and eye-tracking (Williams, Janelle, \& Davids, 2004). Finally, the cognitive approach allows the collection of accurate and objective measures on perceptive and decision skills as the variables measured are controlled and can be internally validated.

\section{Main skills studied}

Cognitive skills encompass the ability to receive, store, retrieve and process information (Bernstein, Penner, Clarke-Stewart, \& Roy, 2011). They are necessarily heavily solicited in handball because players' actions involve tactic choices. The necessity to reason, solve problems and make decisions is therefore permanent throughout the game (Wagner, Finkenzeller, Würth, \& Von Duvillard, 2014). Many authors associated decisionmaking with executive functions (Diamond, 2013; Salthouse, 2005), which are involved in complex cognition such as solving novel problems, modifying behavior based on new information, generating strategies or sequencing complex actions. All of that is linked to the game activity of any player of collective sport. Importantly, different cognitive skills are associated with decision-making abilities and studied in the cognitive approach (Tenenbaum \& Bar-Eli, 1993). Anticipation, which is an executive function referring to the efforts to predict intentions of one's opponent, appears to be crucial to high level performance in sports (Williams \& Ward, 2007). Attention, which is the ability to sustain focus on a particular object, action or thought (Reynolds, 2015), can be divided into sustained attention (focus for long periods), selective attention (focus on one stimuli among several), and divided attention (focus on several stimuli) 
(Barkley, 1997). Attention plays an important role in team sports because players need to monitor multiple information such as the position of their teammates and opponents (Memmert, Simons, \& Grimme, 2008). Visual perception is also an important component of decision-making. It gives the athlete complex information allowing them to plan their actions (Williams, Davids, \& Williams, 1999). Memory is often studied in the cognitive approach and corresponds to the information stored for a long (long-memory) or a short period (short-term and working memories) (Cowan, 2008). Working memory allows one to recall relevant information, crucial to have in mind in order to think and act appropriately (Miyake \& Shah, 1999). Finally, reaction time is part of the response time and is defined as the time between the introduction of a stimulus and the beginning of the motor response (McMorris, 2004). Short reaction and response times give an obvious advantage when facing an opponent (Robinson, 2014). They are associated with various elements in handball and can be shorten with practice (Wagner et al., 2014).

\section{The naturalistic approach}

\section{Presentation}

The most recent method is the naturalistic approach, which takes into account the context of the decision and the relationship between actors. It relies on two main approaches: semiological approach and theoretical models. The semiological approach, which is based on the theory of the situated action (Suchman, 1987) and the concept of the course of action. The course of action is a chain of activity units that is meaningful for the actor (Theureau, 2006). Individual and collective activities are studied based on self-reporting information. The semiologic approach uses essentially qualitative methods such as self-confrontation (Lyle, 2003) or explanation interviews (Vermersch, 2018). In theoretical models, the individual activity is examined with the recognition primed decision model (RPD) (Klein, 1997) or the situation awareness (Endsley, 1995). The collective activity, on the other hand, is examined through team situation awareness (Endsley \& Jones, 2001) and the shared mental models (Mathieu, Heffner, Goodwin, Salas, \& Cannon-Bowers, 2000). Whereas in the cognitive approach participants seek to maximize their performance for a given task, in the naturalist approach, participants seek only to have satisficing behaviors in response to real constraints. In the naturalistic approach, studies showed that experts take into account multiple elements to make a decision, including the score, the opponents and teammates actions, the ball trajectory... (Bossard \& Kermarrec, 2011; Macquet \& Fleurance, 2006). It has been shown that expert players are able to recognize the situations faster than novices, allowing them to make better decisions (Johnson \& Raab, 2003).

\section{Main skills studied}

The analysis of decision-making processes in team sports based on the naturalistic approach highlighted the role of a tactical decision, for both offensive and defensive actions (Bossard, De Keukelaere, Cormier, Pasco, \& Kermarrec, 2010; Macquet, 2009). A tactical decision involves all the individual skills you need to perform in an opposition situation (Gréhaigne, 1999). First, the relevant cues picked up in the game environment constitute essential information for players to make a decision (Bossard \& Kermarrec, 2011). The perception of these relevant cues appears linked to visual attention, mostly selective and divided attention. Players need to response to questions such as: "What does my opponent want to do? Am I able to overtake them? Which solution or option is the simplest?" (Johnson \& Raab, 2003; Macquet, 2009). All these elements were mainly expressed by participants through interviews, but also observed in gaze analysis. The gaze behavior examines the number and the duration of gaze fixations on relevant visual cues (Raab \& Johnson, 2007). Second, the experience and knowledge, acquired through practice, contribute to make a judgment adapted to the situation (Mouchet \& Bouthier, 2006). Experience helps players to enhance their understanding of the different actions, allowing them to anticipate the opponents' intentions and adjust their own actions accordingly. This means that experience plays an important role in anticipation (Williams et al., 1999). During interviews, expert handball players explained that they are usually able to guess what is about to happen and can therefore adjust their actions accordingly (Lenzen, Theunissen, \& Cloes, 2009). Third, players need to understand the expectations of their partners and their opponents (Macquet, 2009; Mouchet \& Bouthier, 2006) to make their decisions in a given situation. Relying on general concepts in team sports and specific concepts in handball, players try to guess what other players will do (Lenzen et al., 2009).

In addition, the ball carrier in team sports needs to decide what to do with. This option can be chosen among several that the player has to imagine, relying on their cognitive processes while being under pressure (Raab, 2002). The different options generated are based on an understanding of the current situation, knowledge and previous experiences (Macquet, 2009). For instance, a ball carrier has different possibilities: throwing, passing the ball to a teammate, dribbling and running in different directions, feinting an opponent or entering a duel with them. Their choice depends on the perceived cues, the player's skills, their experience, but also on contextual elements, and results from existing interactions between them and their environment (Johnson \& Raab, 2003; Macquet, 2009). Finally, the naturalistic approach also examines collective skills: the coordination between players, the development of a strategic plan and the shared awareness (Bourbousson, R'Kiouak, \& Eccles, 2015; De Keukelaere, Kermarrec, Bossard, Pasco, \& Deloor, 2013; Saury, Durand, \& Theureau, 1997). Considering the collective activity, based on the analysis of each individual course of action, allowed to better understand how players interact and what they rely on to make a decision (Bourbousson, Poizat, Saury, \& Sève, 2008). 


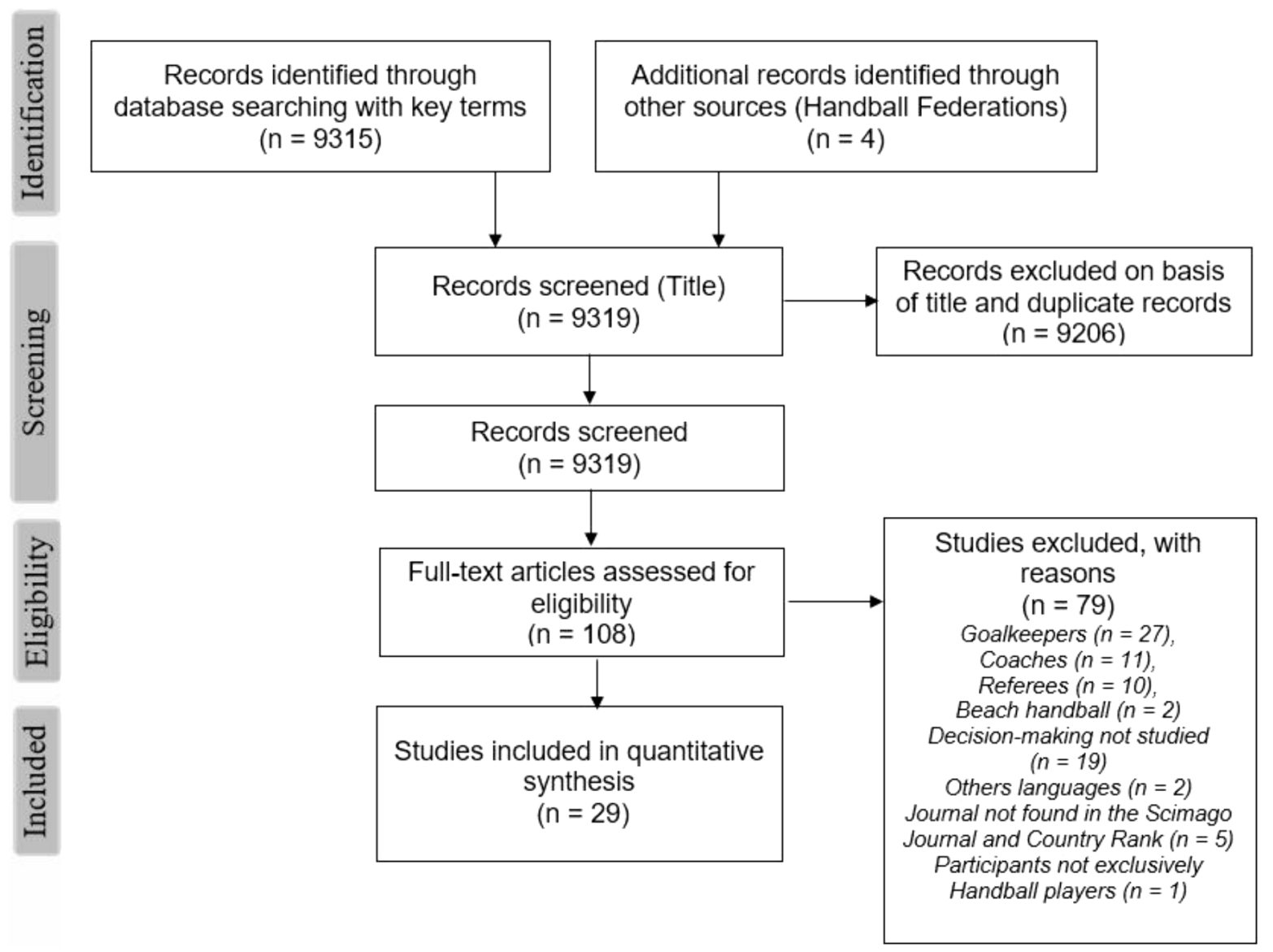

Fig. 1. PRISMA guidelines.

\section{Aim of the current study}

As aforementioned, the aim of this review is to summarize current literature on decision-making in handball. We have focused on the following key points: 1) the approaches and theoretical models used in the current literature to study decision-making in handball; 2) the methods used and variables studied (independent and dependent); 3) the main results and handball skills involved in decision-making; and 4) current limitations and perspectives.

\section{Method}

\section{Protocol}

Published studies detailing the implementation of decision-making methods in handball were reviewed using the Preferred Reporting Items for Systematic Reviews and Meta-Analyses guidelines (Moher, Liberati, Tetzlaff, Attman, \& PRISMA GROUP, 2009). The process is detailed within Figure 1.

\section{Information sources and search strategy}

The search was limited to studies published between January 1990 and June 2019 (the number of publications published before 1990 being negligeable) (Prieto, Sampaio,
\& Gómez, 2015). We used the following keywords and their combinations: "Handball", "Team handball", "Cognition", "Executive Function", "Cognitive function", "DecisionMaking", "Memory", "Anticipation", "Perception", "Attention", and "Option Generation" as well as their related terms and synonyms in the following electronic databases: PubMed, SPORTDiscus, PsycArticles, PsychINFO, ScienceDirect, European Handball Federation. In addition, a manual reference search was performed on the records found. Documents that were not initially located in full text were requested directly to the main authors.

\section{Eligibility criteria}

Full-text articles were eligible for inclusion in this systematic review if the studies filled the following requirements: (a) published in scientific journals (Peer reviewed); (b) written in English or French; (c) published in a journal included in the database Scimago Journal and Country Rank; (d) examined only dependent variables associated with decision-making; (e) tested a cohort composed exclusively of handball players or provided separate results for this group; (f) concerned novices in handball if this group was compared to expert handball players; (g) focused exclusively on field player's decisionmaking. 


\section{Extraction of data of interest}

For each article included in the analysis, the following data were extracted: authors and year of publication, main goal, characteristics of the handball player cohort, theoretical framework, methods used and variables examined, main results and main skills investigated, limits and perspectives mentioned. These different categories form the different columns of the Tables 1 and 2. We divided each article into two categories (cognitive approach $[\mathrm{C}]$, and naturalistic approach $[\mathrm{N}]$ ), three first order themes for the cognitive approach (the organization of the knowledge [CK], the memory process $[\mathrm{CM}]$, and the perceptive strategies $[\mathrm{CP}]$ ), two first order for the naturalistic approach (semiological approach [NS], and naturalistic decision-making $[\mathrm{NDM}]$ ), two second order themes for the NS (Individual [NSI] and Synchronized [NSS] bottom-up interviews) and two second order themes for the NDM (Individual [NDMI] and Collective [NDMC] models). For the cognitive approach, studies were associated with one of the first order themes according to the tasks performed by the participants and the variables measured. Recognition and specific tasks with handball images were associated with CK. Recall and memory tasks were associated with CM. Perceptive, reaction tasks and evaluation of the executive functions were associated with CP. The NS corresponds to the course of action (Theureau, 1992), which can concern individual (NSI) or synchronized (NSS) bottom-up interviews. The naturalistic decision-making (Klein, 1997) corresponds to a set of theoretical models: the RPD model and the situation awareness in one hand (NDMI), and the shared mental models and the team situation awareness (NDMC) on the other hand. Moreover, some authors are clearly associated with the theoretical models cited above such as Theureau, or De Keukelaere for the NS approach and Klein for the NDM approach, that contributes to repartition of the different studies. We proposed a classification for each study: CP, CM, CK, NSI, NSS, NDMI, NDMC (see Tabs. 1 and 2).

We specified for each study: 1) the different tests and tasks used, 2) the independent and dependent variables (VI and VD respectively), 3) the qualitative or quantitative methods, 4) the specific or non-specific tests. A test was considered as specific if the task is closed to player's action during a match. Then, we described the main results and the specific skills associated, the kind of decision participants must make (individual/collective, offensive/defensive), and the main limits and perspectives proposed by authors (see Tabs. 1 and 2).

\section{Reliability of the coding process}

Two coders (first and second authors) classified all of the articles into the different categories and themes. Reliability points were estimated using Kappa index $(k)$, which represents the normalized proportion of interobserver agreement in excess of what would be expected based on chance or random assignments. We used
Statistica software version 13.3, which calculates both general and conditional coefficients and tests the statistical significance of agreement among two observers assigning objects to nominal scales. The overall Kappa revealed a considerable rate of agreement among the different coders $(k=0.95 ; z=9.62, p<0.0001)$. All the conditional coefficients were also high and significant (see Tab. 3) taken as a whole, these results showed an acceptable reliability of the coding. The coding revealed the lack of the NSS code, meaning that no study relied on the synchronized bottom-up interviews.

\section{Results}

The results highlighted the following key points, presented in the introduction: 1) the approaches and theoretical models, 2) the methods and variables studied, 3) the main results and handball skills studied, 4) the main limits and perspectives. The cohorts examined in these studies were composed on average of 69 participants (from 6 to 332). Seventy-six percent of participants were men and $50 \%$ are adults (as specified in Tabs. 1 and 2).

\section{Approaches and theoretical models}

The cognitive approach was used in 19 studies (65\%), whereas the naturalistic approach was used in 10 studies (35\%) (see Tabs. 1 and 2). We noted that more than a third of the studies did not specify the theoretical framework used. The lack of information regarding the theoretical approach used make understanding the results more difficult and thus hinder scientific progress. The principal aspects studied in the cognitive approach were perception and psychomotor abilities (12 studies, 41\%), whereas memory process was examined in 4 studies $(13 \%)$ and knowledge in 3 studies (10\%). In the naturalistic approach, the principal category studied was naturalistic decision-making (7times in individuals and twice in a collective approach, $24 \%$ and $7 \%$ respectively), whereas the semiologic approach was examined only once in individuals (3\%). Moreover, the RPD model was used only 3 times $(30 \%)$, while is a major theoretical model concerning this approach. It is important to note that the collective dimension in the semiologic category was not studied.

\section{Methods and variables studied associated with handball decision-making}

The principal independent variables examined in the cognitive approach were the expertise and the experience in 10 studies $(53 \%)$. The reaction and decision times constituted the main dependent variables measured (9 studies, $47 \%$ ), whereas the accuracy was examined in 6 papers $(31 \%)$ and the quality of the decision only once $(5 \%)$. Eye-tracking data and collective cognitive skills were not assessed in studies using this approach. When it's specified, the game's phases examined corresponded essentially to offensive phases (6 papers; $67 \%$ ) and to 


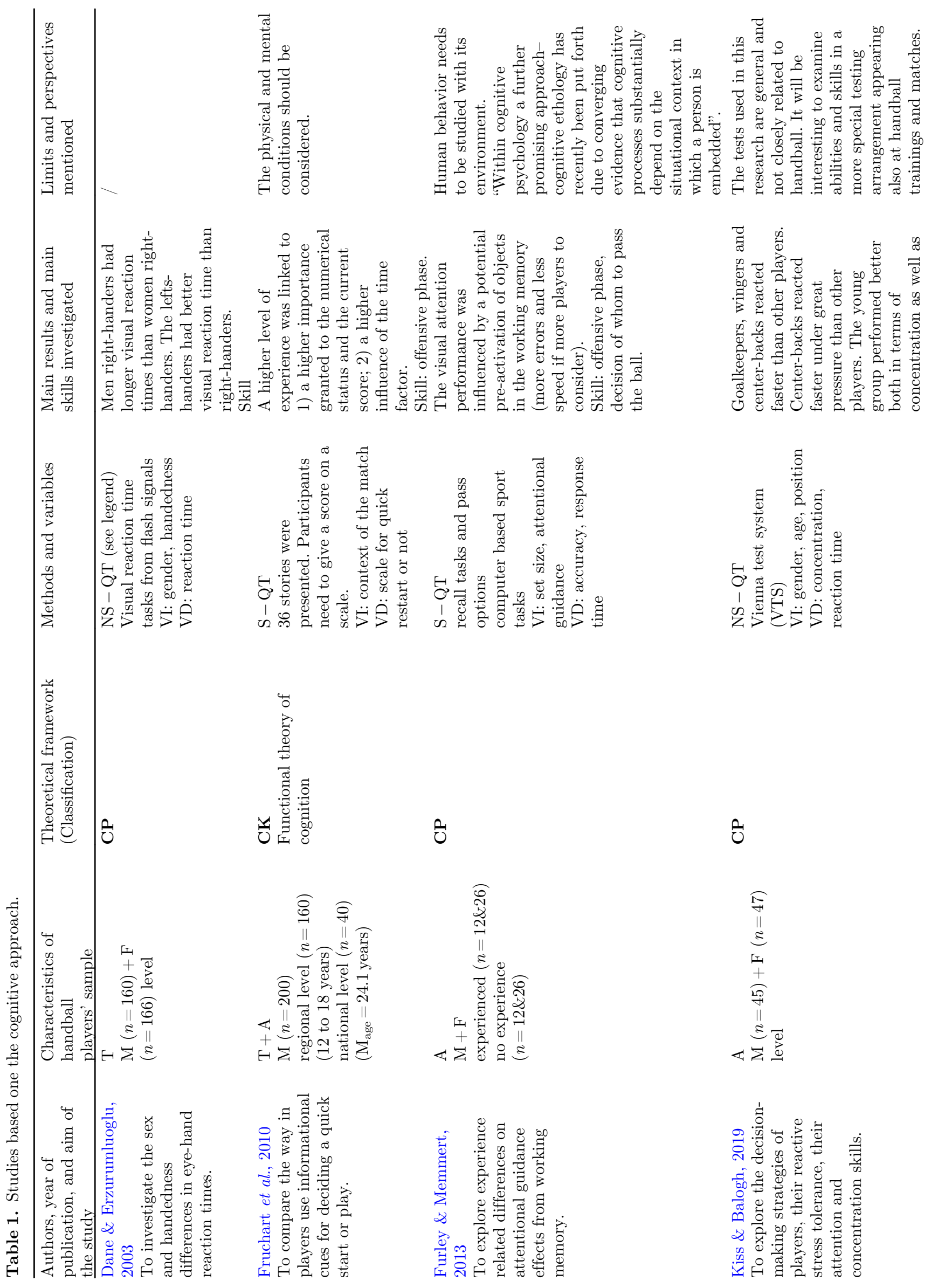




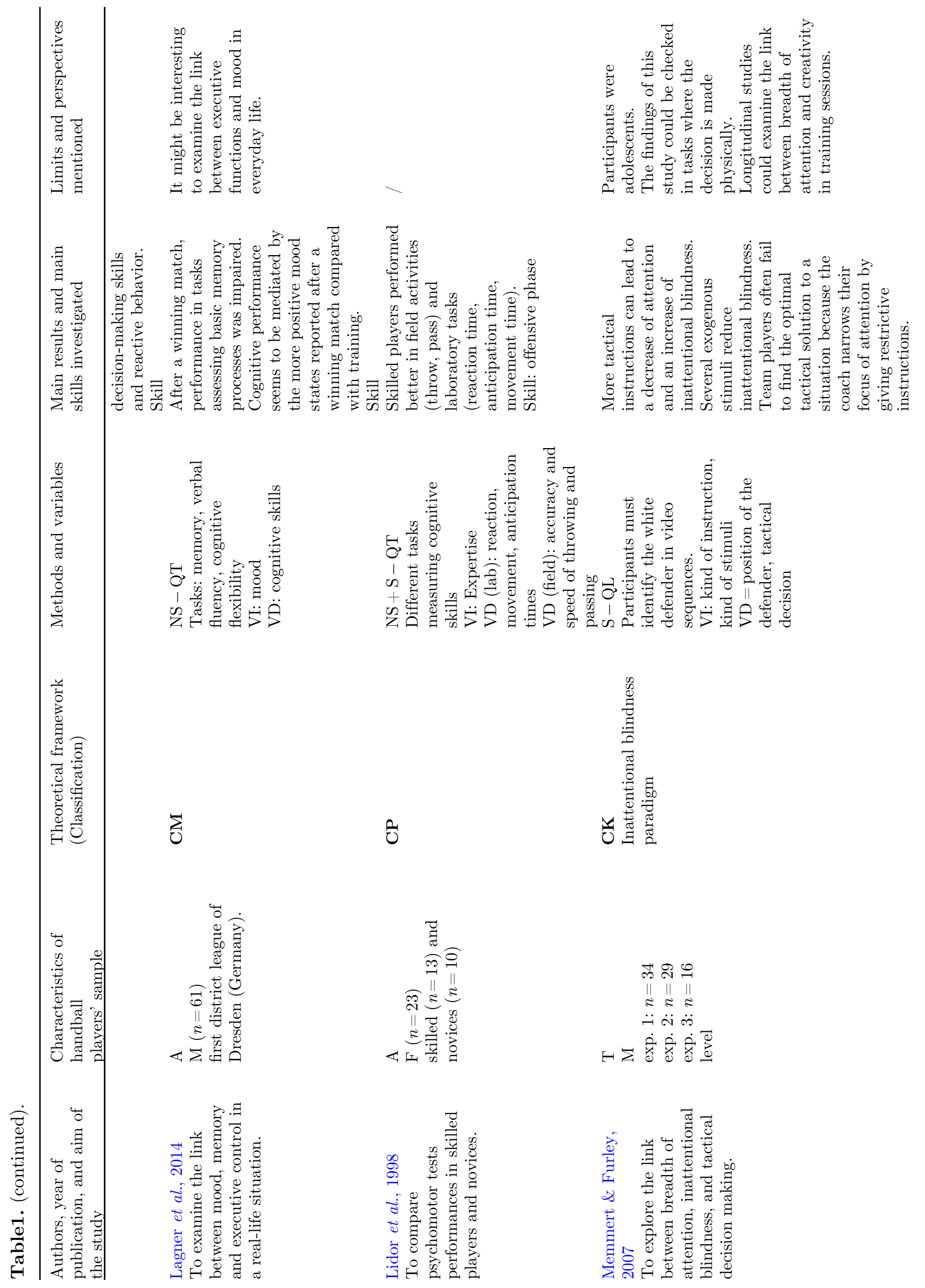




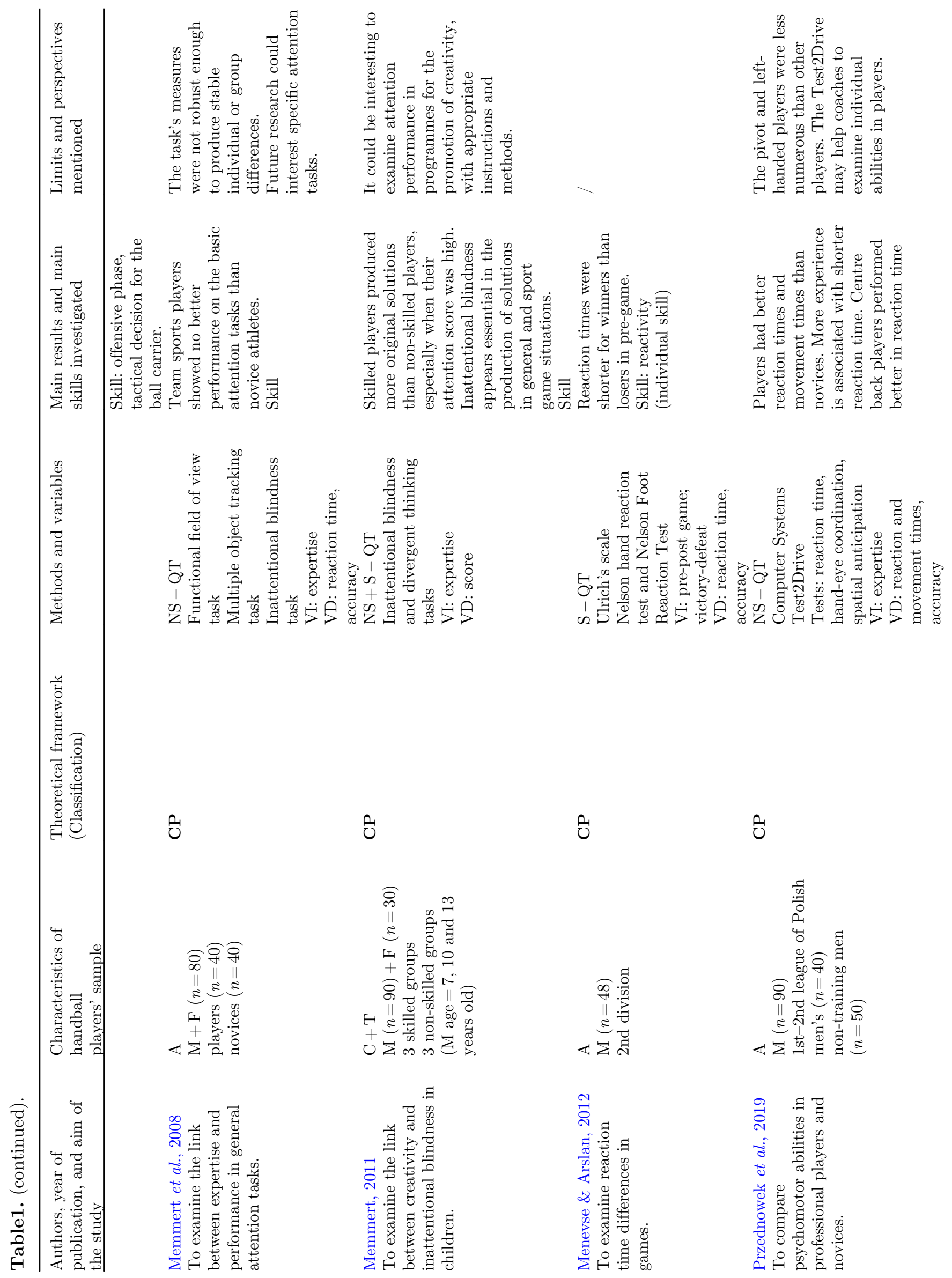




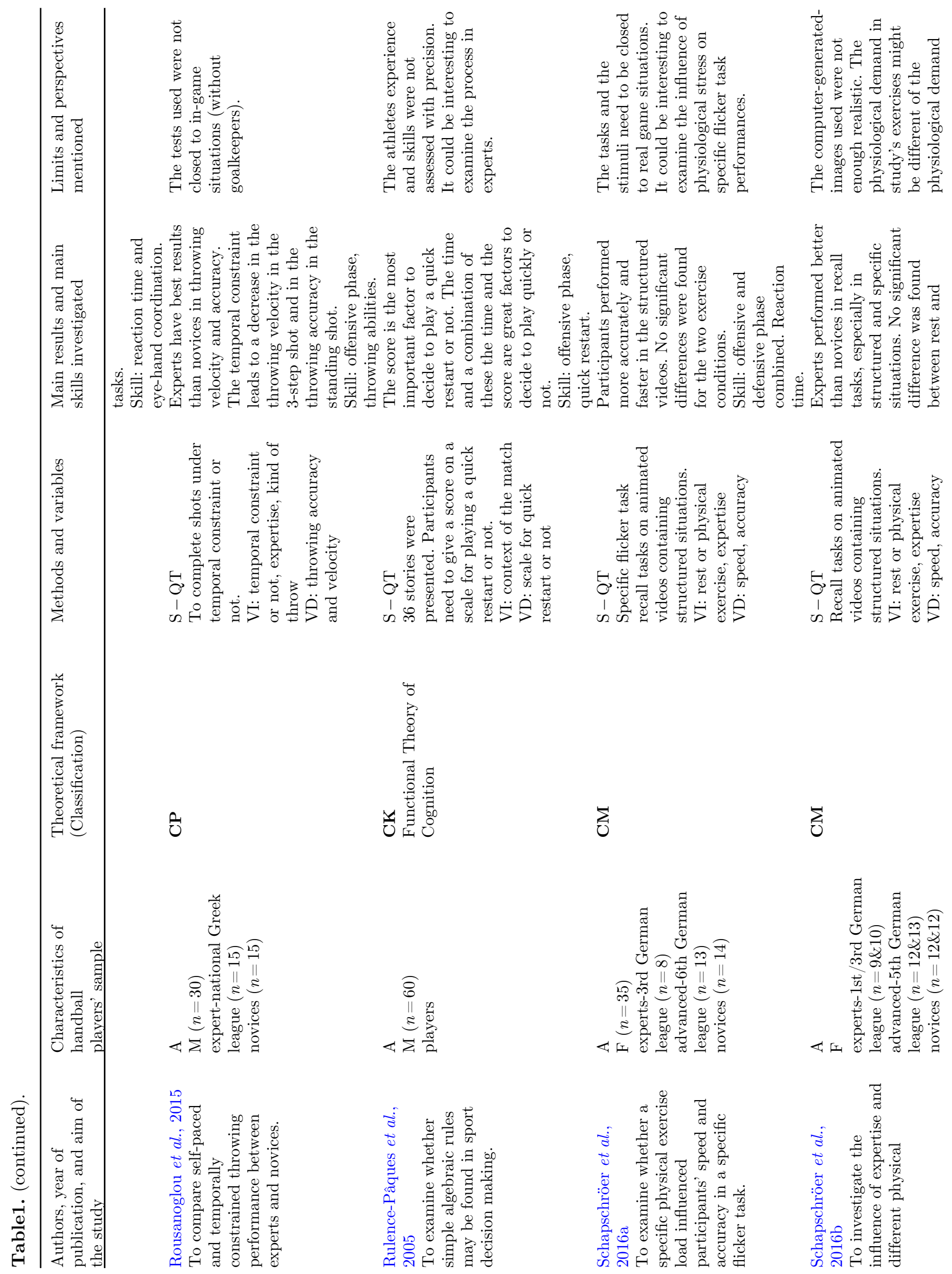




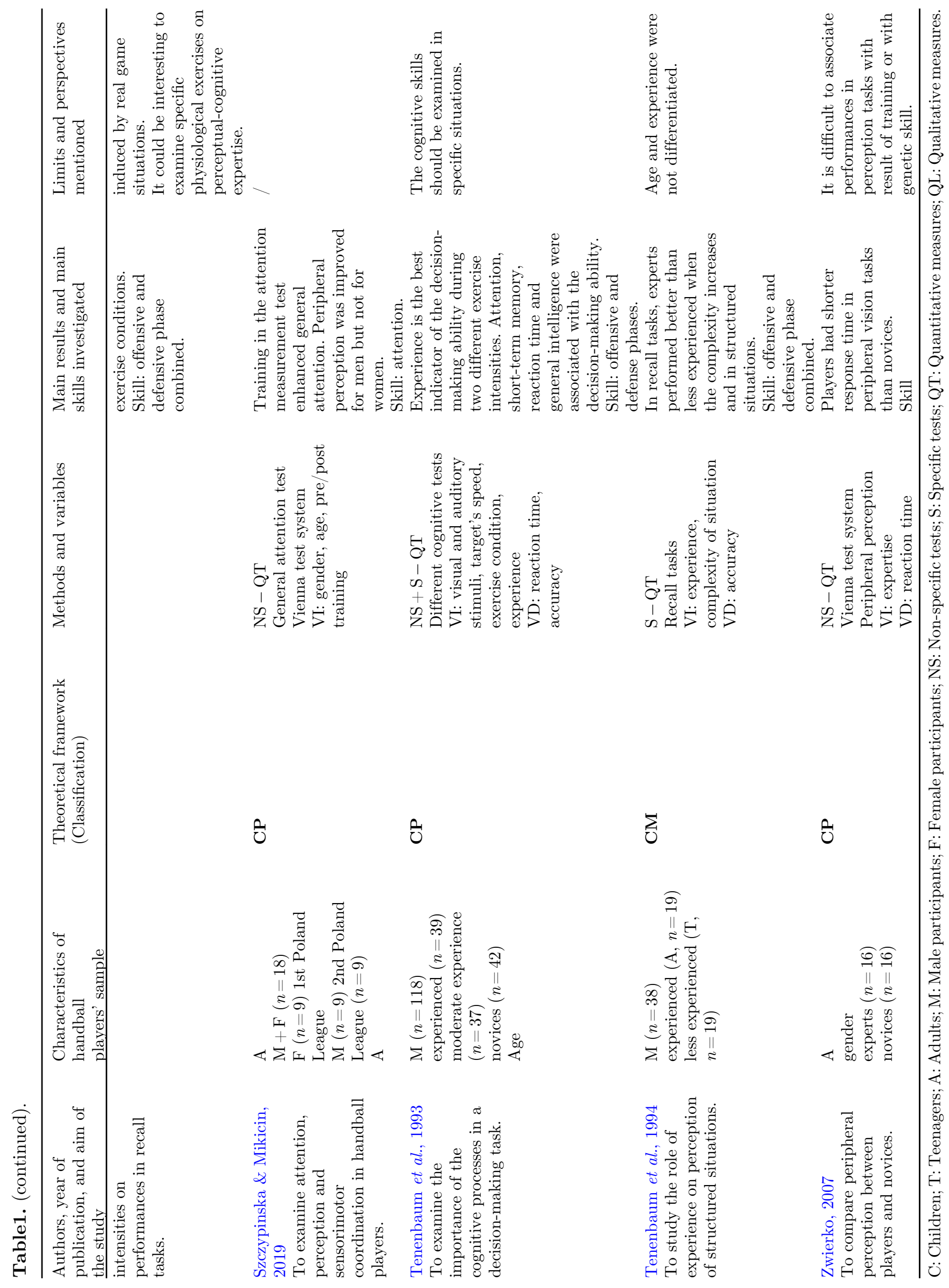


G. Bonnet et al.: Mov Sport Sci/Sci Mot 2020, 110, 1-19

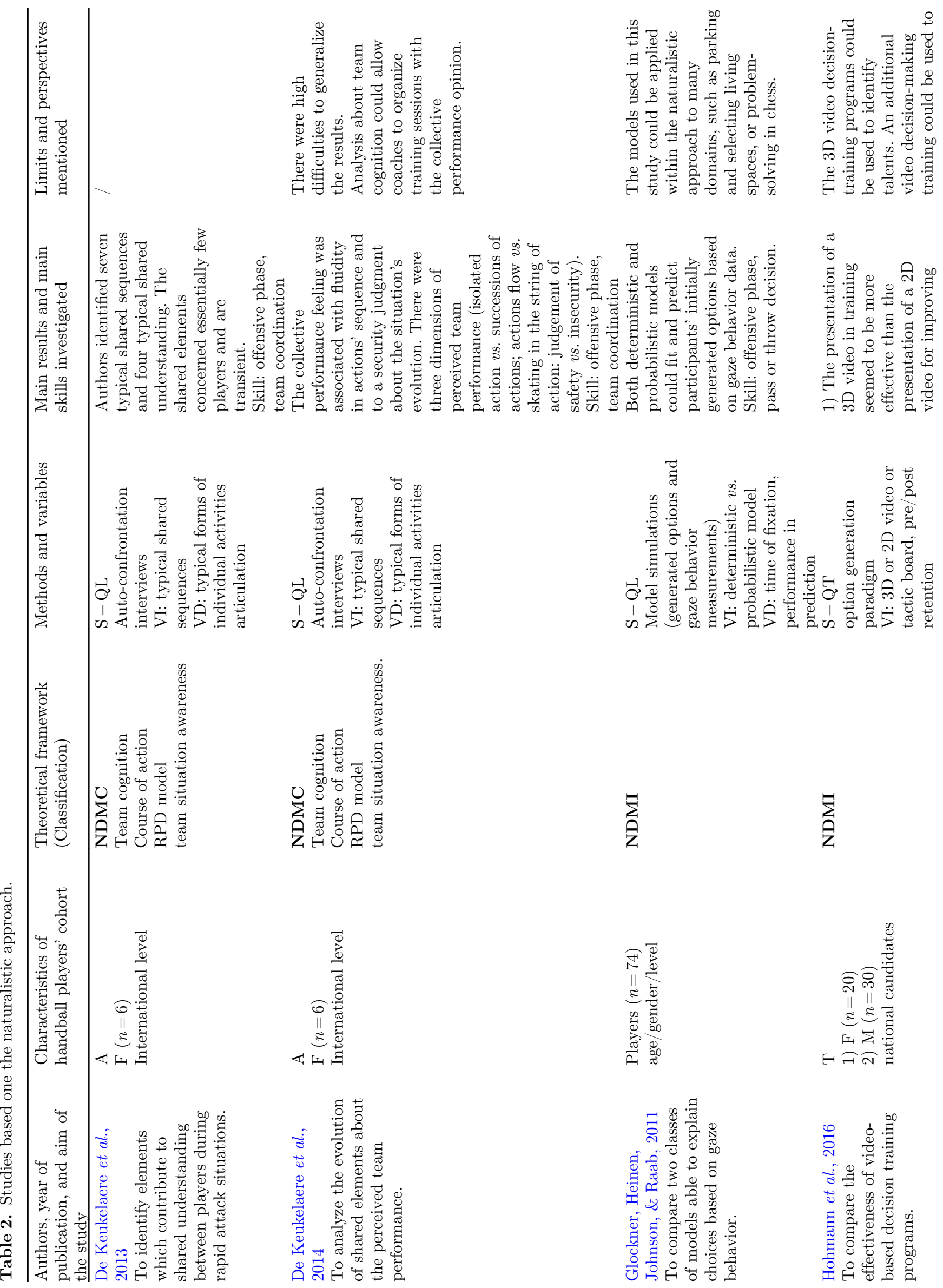




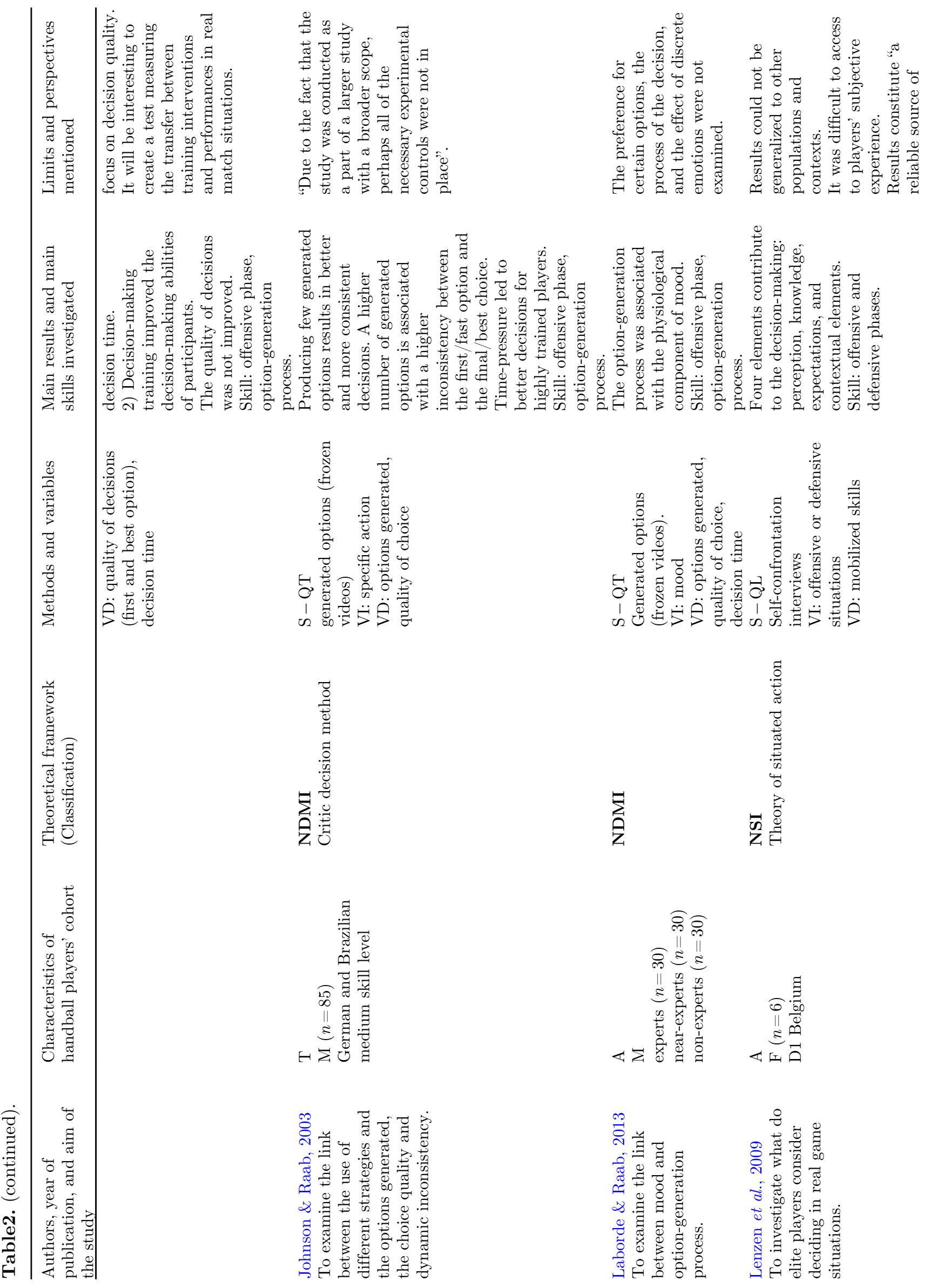




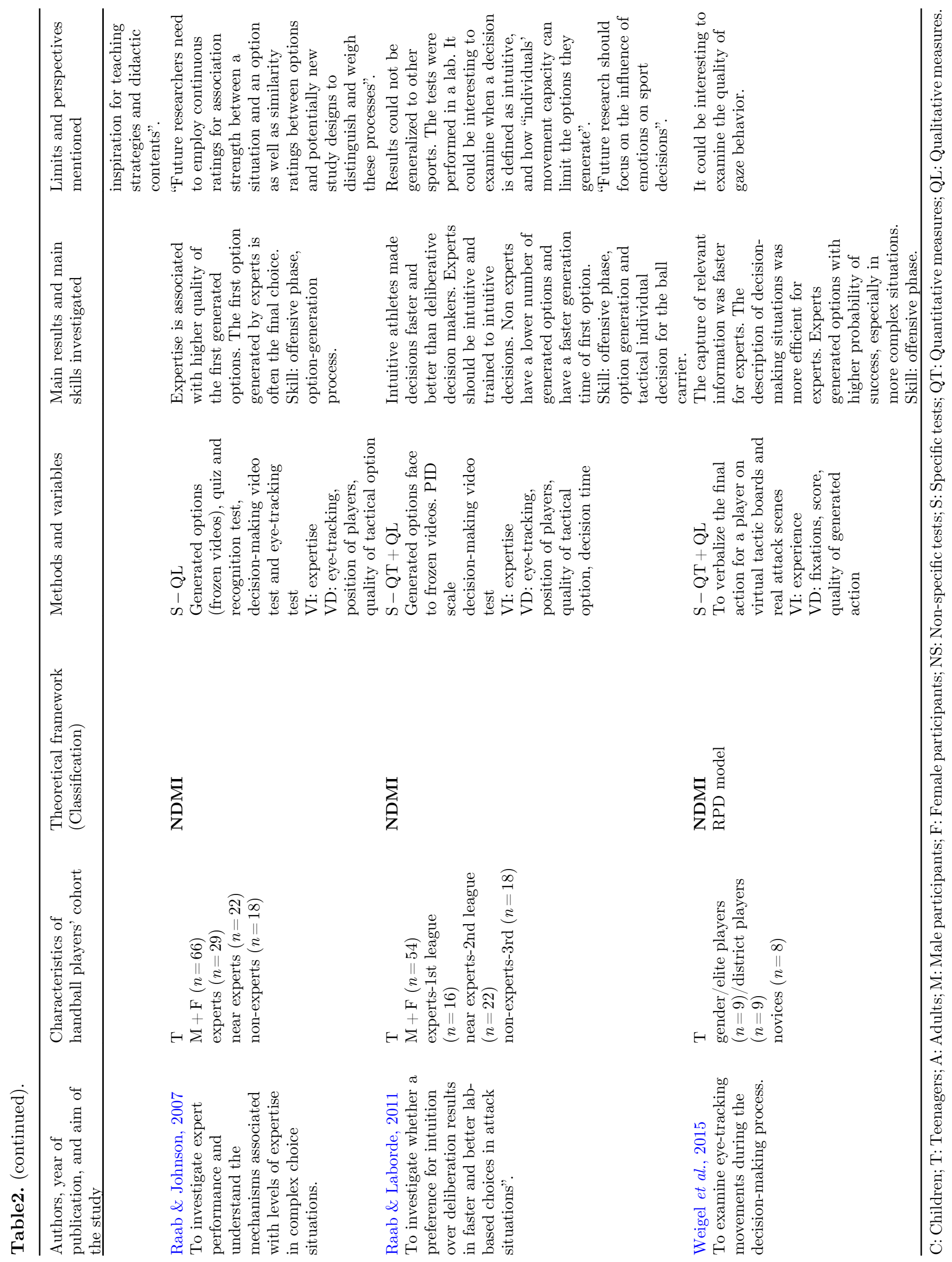


Table 3. Inter-rater agreement.

\begin{tabular}{llll}
\hline Categories & Kappa & $z$ & $p$ \\
\hline CK & 1 & 5.38 & $<0.001$ \\
CM & 0.87 & 4.72 & $<0.001$ \\
CP & 0.93 & 5.01 & $<0.001$ \\
NDMI & 1 & 5.38 & $<0.001$ \\
NDMC & 1 & 5.38 & $<0.001$ \\
NSI & 1 & 5.38 & $<0.001$ \\
NSS & $/$ & $/$ & $/$ \\
\hline
\end{tabular}

a combination between offensive and defensive phases (3 papers; $33 \%$ ). However, 10 publications did not specify the phase studied $(53 \%)$, meaning that tasks were not realized in a specific context. Interestingly, only two studies integrated participants into an imagined specific context closed to handball (Fruchart, Pâques, \& Mullet, 2010; Rulence-Pâques, Fruchart, Dru, \& Mullet, 2005).

In the naturalistic approach, the principal independent variables examined were expertise and experience ( 3 studies, $30 \%$ ). The quality of the generated options constituted the main dependent variables measured (6 studies, 60\%), whereas the eye-tracking data were examined three times $(30 \%)$ and the collective cognitive skills twice (20\%). The accuracy was not measured in this approach. The measurements represent qualitative variables in 5 out the 10 studies $(50 \%)$, quantitative variables in 3 studies $(30 \%)$, and both in 2 studies (20\%). Concerning the handball phases examined, 9 out the 10 studies examined only offensive phases (90\%). The tenth study examined both offensive and defensive actions.

\section{Main results and handball skills studied Cognitive approach}

The studies examined only individual cognitive skills and mainly interested on the playmaker activity. First, Tenenbaum et al. (1993) revealed that short-term memory was a significant predictor of the decision-making ability. Globally, expert players performed better than novices in these tasks (Furley \& Memmert, 2013; Schapschröer et al., 2016b; Tenenbaum, Kolker, Bar-Eli, \& Weinberg, 1994), especially when the complexity increased (Furley \& Memmert, 2013). However, experts performed better only when the proposed situations are structured (Schapschröer et al., 2016a; 2016b; Tenenbaum et al., 1993). Furley \& Memmert (2013) explained the superiority of experts by a greater ability to use their working memory and visual attention. However, authors noted that the visual attention is influenced by a potential pre-activation of objects in the working memory. Then, Lagner et al. (2014) revealed that the mood states mediates positively cognitive performances and the memory processes.

Second, perceptive skills appear essential in decision tasks (Tenenbaum et al., 1993), including the reaction and response times, which represent the principal data measured in handball. Studies revealed that these skills are strongly linked to expertise, experience, gender, laterality or position in the field. The reaction time is shorter for skilled players than novices (Lidor, Argov, \& Daniel, 1998; Przednowek et al., 2019; Rousanoglou, Noutsos, Bayios, \& Boudolos, 2015; Schapschröer et al., 2016a; Zwierko, 2007). Menevse \& Arslan (2012) revealed that tournament's winners have shorter reaction time. Experience is also a factor to shorten response time in peripheral vision tasks (Zwierko, 2007), or reaction time in simple reaction tasks (Przednowek et al., 2019). The reaction time is shorter for left-handers than right-handers players and for men than women (Dane \& Erzurumluoglu, 2003). Similarly, the wings and central back players react faster than other players (Kiss \& Balogh, 2019; Przednowek et al., 2019).

Third, Tenenbaum et al. (1993) underlined the role of attention in experts to identify relevant information and ignore irrelevant one. Several studies in the 2000's confirmed that visual attention was strongly associated with greater performances in decision-making tasks (Memmert, 2011; Memmert \& Furley, 2007; Memmert et al., 2008). Guided by working memory (Furley \& Memmert, 2013), performances in different attention tasks were associated with the amount of instruction received and the type of stimuli. These results reveal that attention ability improve with training (Szczypinska \& Mikicin, 2019). Nonetheless, too many instructions given by a coach can lead a decrease of the attention (Memmert \& Furley, 2007) and consequently potential difficulties of understanding the instructions or to apply them. Then, the anticipation ability appears to be superior for expert players than novices (Lidor et al., 1998).

Finally, two studies (Fruchart et al., 2010; RulencePâques et al., 2005) focused on the mobilization of knowledge, relying on the functional theory of cognition (Anderson, 2008). They revealed that the score is the main factor, which allows players to decide a quick restart of play or not, no matter the level of players' experience. However, these authors indicated that numerical status is more important for experienced players than for novices.

\section{Naturalistic approach}

Based on the semiologic approach and particularly on the theory of situated action (Suchman, 1987), Lenzen et al. (2009) revealed that four elements contribute to decision-making. The first one is the ability to perceive relevant cues. The second one corresponds to the base of fundamental and specific knowledge. Then, players need to understand the expectations from coach, partners and opponents. Finally, players need to take into account contextual elements such as the score, the opponent's level or the stake's match.

Based on an heuristic approach, Raab \& Laborde (2011) studied the link between intuition and the decisionmaking. Intuition was defined by the authors as an involuntary judgment based on previous learning and experiences. Authors revealed that intuition allows to decide faster and better for experts. This study gets closer to the RPD model, which identifies the first reasonable 
reaction from the relevant cues and situations already experienced. Moreover, expert players generate the options with the highest probability of success, especially in more complex situations (Johnson \& Raab, 2003; Raab \& Johnson, 2007; Weigel, Raab, \& Wollny, 2015; for a review see Raab, De Oliveira, \& Heinen, 2009). Furthermore, experts generate less options than novices but with higher quality, the first one being the best (Johnson \& Raab, 2003; Raab \& Johnson, 2007). The decision time in the option generation process was strongly associated with a better efficacity in training with 3D video than 2D video (Hohmann, Raab, Schlapkohl, \& Obeloer, 2016). In addition, Glockner et al. (2011) revealed that the study of the generated options, based on behavior data, could be predicted by both deterministic and probabilistic models. Then, Laborde \& Raab (2013) revealed that the option-generation process was associated with the physiological component of mood.

Finally, only two studies focused in the collective dimension of a decision through the evaluation of team cognition and the team situation awareness (De Keukelaere et al., 2013; De Keukelaere, Kermarrec, Bossard, \& De Loor, 2014). The team situation awareness studies the cognitive elements integrated into the collective organization and shared by players on the field and their evolution during a played action. Authors revealed that the shared elements are articulated around a collective plan or an adaptation to the context. Their layout in the field during offensive phases depends on the number of players who shared these elements (De Keukelaere et al., 2013). Additionally, the collective performance appears better for players when actions are fluent and safety (De Keukelaere et al., 2014).

\section{Limits and perspectives}

The limitations proposed by authors studying decision-making abilities concerned 1) the sample of participants, 2) the context of the decision, 3) the generalization of the results and 4) the prioritization of the generated options. First, the number of participants was sometimes less than 50 (Menevse \& Arslan, 2012; Przednowek et al., 2019). Two studies suggested that evaluating decisionmaking ability in teenagers might have certain limitations (Memmert \& Furley, 2007; Tenenbaum et al., 1994). The lack of precision in measuring the experience of participants appeared also a limitation to study these skills (Rulence-Pâques et al., 2005; Tenenbaum et al., 1994). Second, the study of decision-making skills, according to the cognitive approach, does not take into account the context of the decision, since the objective is to simplify and better control the different variables examined. Several studies suggested that it was a limitating point because the tests used and the executed tasks were too far from the in-game decisions processes (Furley \& Memmert, 2013; Kiss \& Balogh, 2019; Lagner et al., 2014; Memmert, 2011; Memmert et al., 2008; Rousanoglou et al., 2015; Schapschröer et al., 2016a, 2016b; Tenenbaum \& Bar-Eli, 1993). Zwierko (2007) suggested that the results concerning the responsiveness to visual stimuli did not allow them to ascertain whether better performances were due to a genetic superiority or resulted from training. Third, three studies in the naturalistic approach highlighted the difficulties to generalize the results. This was due to the particular and reductive context of the decisions studied and the difficulty to assess the experience of the players (De Keukelaere et al., 2013, 2014; Lenzen et al., 2009). Finally, in option generation process, the number of options and the speed at which they were generated are often examined but the prioritization of one option versus the others was not enough examined (Laborde \& Raab, 2013; Raab \& Johnson, 2007).

Concerning the main perspectives suggested by authors, it appears necessary to examine elements, which could influence decision-making. Authors cited different components such as mental and physical conditions (Fruchart et al., 2010; Schapschröer et al., 2016a), in-game performances (Memmert, 2011), mood state (Raab \& Laborde, 2011), and creativity, especially in longitudinal study (Memmert \& Furley, 2007). Moreover, the individual's opinion could be examined in future studies to better understand their importance in the collective performance (De Keukelaere et al., 2014). Several authors suggested that the study of the decision-making ability could be applied to coaches and professors in order to enhance their teaching skills. It could guide the practice of team sports from a cognitive point of view (Lenzen et al., 2009; Szczypinska \& Mikicin, 2019). In training, the 3D video appears to be a good tool to enhance the player's ability to better decide (Hohmann et al., 2016). Finally, Furley \& Memmert (2013) suggested that an "ethologic" approach could be used to study decision-making and analyze cognitive processes in a real decisional context. In this way, this approach would respond to suggestions made by authors in the cognitive approach (Furley \& Memmert, 2013; Kiss \& Balogh, 2019; Schapschröer et al., 2016b; Tenenbaum \& Bar-Eli, 1993).

\section{General discussion}

\section{Specifying the theoretical framework}

The theoretical framework was rarely specified or explained in the included studies, which makes understanding and comparing the results particularly challenging. Most of these studies relied on the cognitive approach and quantitative methods, representing more than two thirds of the included papers about handball. The naturalistic decision-making approach was less used, particularly in its collective dimension. This was also true for the semiologic approach, which was used only in one study and only in an individual approach. We highly recommend that future studies specify the theoretical framework in order to facilitate the understanding and the interpretation of the results. Importantly, future studies should also link the results to the existing theoretical models in order to draw theoretical implications. 
In addition, the cognitive and the naturalist approaches appear complementary to consider the decision-making as an alternation between simple and complex decisions. The cognitive approach identifies the knowledge and relevant cues used to decide in an easily identifiable situation. However, the naturalistic approach identifies either the parameters of an emerging decision in a dynamic and collective situation (Johnson, 2006; Mouchet, 2005; Weigel et al., 2015), either a recognition process (Klein, 1997). This complementarity between the two approaches has already been shown by Ericsson \& Smith (1991). They proposed a framework to study the expert performance that relied on the two approaches. The cognitive approach would be used in a first phase to capture and identify cognitive skills, and the naturalistic approach would be used in a second phase to examine the mediating mechanisms involved in the expertise development. They used questionnaires and interviews to highlight the role of the practice years. For instance, players declare sometimes that they make a decision with "yeux fermés", meaning that the decision might be automatized or intuitive. Examining the factors that differentiate a deliberate decision from an automated decision appears to us as a relevant research axis in handball. Moreover, an "ethologic" approach which combines the cognitive and the naturalistic ones, appears interesting to study decision-making and cognitive skills in a context closed to the in-game handball context (Furley \& Memmert, 2013). Considering the collective dimension in the decision using methods developed recently for other sports (Araújo, Silva, \& Davids, 2015; Kermarrec, 2015; Sève, Bourbousson, Poizat, \& Saury, 2009) would be an asset to understand how players get to coordinate their actions and make decisions sometimes without defined strategies.

\section{Great variety of methods}

Research methods are highly heterogeneous. Similarly, the profile of the subjects studied varies, especially regarding the level of expertise. Indeed, expertise is a very subjective aspect and is hard to evaluate and standardise (Swann, Moran, \& Piggott, 2015). There is also a lack of studies involving female participants. Very few studies looked at how teenaged players make a decision in comparison to adults, which would be an interesting line of work (Tenenbaum et al., 1994). Indeed, examining the development of the decision-making abilities over the years would provide valuable data that could greatly contribute to the field. The perceptive skills were mainly studied in the cognitive approach, but few studies focused on the executive functions. However, executive functions are heavily solicited in handball because they help generating strategies and adjusting behavior according to the perceptible information (Diamond, 2013; Salthouse, 2005). When Verburgh, Scherder, Van Lange, \& Oosterlaan (2014) studied executive functions in soccer, they found that highly talented players showed superior motor inhibition than amateur players. Long-term memory is not studied in handball but appears associated with action control and perceptualcognitive structures (Schack \& Mechsner, 2006) and thus would be an interesting aspect to assess.

In the naturalistic approach, the option generation process is often studied and it has been shown in many different sports that the first option generated is usually the best for experts (Belling, Suss, \& Ward, 2015; Farrow \& Raab, 2008; Hepler \& Feltz, 2012). Few studies focused on gaze behaviour associated with the option generation process. However, these studies give quantitative data while the naturalistic approach uses mostly qualitative methods. Experts have a smaller number of gaze fixations and a longer duration of fixation (Savelsbergh, Williams, Van der Kamp, \& Ward, 2002). To our knowledge, no study examined others aspect of team cognition in field handball players, including the shared mental models. Importantly, Debanne, Fontayne, \& Bourbousson (2014) revealed that different kinds of shared knowledge could be used between coaches and players. This is an important finding and we believe that future research in field handball players should also focus on this aspect.

\section{Main results and practical applications}

The studies based on the cognitive approach focused to decisions factors such as the memory processes, the visual attention, the perceptive ability, the reactivity or the anticipation skills. Studies revealed that experts or experienced players performed better than novices in cognitive tasks, both in handball specific and non-specific tests. We could highlight four major findings: 1) working memory and attention appear crucial to perform efficiently in cognitive tasks (Afonso, Garganta, \& Mesquita, 2012), 2), working memory can act as a pre-activator of visual attention, thus facilitating the identification of relevant information (Miyake \& Shah, 1999; Williams \& Ford, 2008), 3) experts need structured situations to perform better and the gap between experienced players and novices increase with complexity, 4) the game score guides tactical decisions regarding how fast players resume the game. These results implicate that high-level performance is associated with an enhance ability to make the appropriate decision. In decision-making tasks, the objective is to manage simple parameters such as the score or the numerical status, and more complex parameters such as players' positions and movements, or the ball position. Therefore, coaches need to train players to listen, collect information, in order to engage their working memory and develop automatisms. Thus, it would be relevant to further investigate the link between executive functions and performances in handball.

The theory of situated action allows to distinguish six elements contributing to the quality of a decision in play: the ability to perceive relevant cues, the fundamental knowledge of handball and playing principles, the guidelines expressed by the coach, the attitude of the partners and opponents, the context of the decision, and the intuitive ability based on experience and training 
(Lenzen et al., 2009). This means that players need to practice looking for relevant cues, taking landmarks in play, sharing typical situations several times in order to increase their experience and their handball specific knowledge. Studies revealed that the decision process is associated with a smaller number of generated options for experts, with the first being the most adequate response (Johnson \& Raab, 2003; Raab \& Johnson, 2007; Raab \& Laborde, 2011; Weigel et al., 2015). In addition, it appears necessary to share situations with temporal and spatial constraints in order to encourage quick and efficient information intake. This means that the ability to collect relevant cues has to be practiced with partners (De Keukelaere et al., 2013, 2014). This collective dimension could be examined also with the semiologic approach. Indeed, the decision appears related to the player's adaptative ability according to the perceived interactions between players in a given situation, and to the creation of a collective identity (Mouchet, 2005).

In the two theoretical approaches, most of the studies were interested in decision-making solely for the ball carrier. However, the field decision-making concerns more roles and more actions. For instance, teammates need to anticipate where they could receipt the ball to provide the ball carrier with appropriate throw solutions, while the opponents need to intercept the ball or neutralize the ball carrier before they throw. Further research should be undertaken to investigate decision-making in defenders or the ball carrier's teammates in order to better understand the different types of recognition processes involved (Kermarrec \& Bossard, 2014). Finally, few studies looked at contextual elements, which could influence decisionmaking. For instance, recent changes in game rules, allowing the use of a seventh player in the field instead of the goalkeeper, might require some strategic adjustments. Thus, it would be interesting to investigate whether this strategic choice increase or decrease the likelihood of winning the game.

\section{Limits and perspectives}

The obvious limitations proposed by authors were strongly linked to the approach used. Indeed, studies which used the cognitive approach considered that the decision was not so closed to a real task of players. Studies which used the naturalist approach revealed that the results could not be generalized. Therefore, it would be interesting to discuss how the performance in decisionmaking tasks could be influenced by the mood states or the fatigue (Phillips, Bull, Adams, \& Fraser, 2002; Royal et al., 2006). The perspectives proposed by authors in handball appears also strongly linked to the theoretical approach used. However, the "ethologic" approach proves to be a relevant way to study the decision-making. Indeed, it would allow to measure cognitive skills in a context closed to real and experienced situations in the field (Furley \& Memmert, 2013). As a result of this review, we encourage researchers to take into account these different points to conduct their future works.
Acknowledgments. The authors have no conflicts of interest that are directly relevant to the content of this review. No sources of funding were used to assist in the preparation of this review.

\section{References}

Afonso, J., Garganta, J., \& Mesquita, I. (2012). Decision-making in sports: the role of attention, anticipation and memory. Rev Bras Cineantropom Desempenho Hum, 14(5), 592-601.

Anderson, N.H. (2008). Unified social cognition. New York: Psychology Press.

Araújo, D., Silva, P., \& Davids, K. (2015). Capturing group tactical behaviors in expert team players.In J. Baker \& D. Farrow (Eds.), Routledge Handbook of Sport Expertise (pp. 209-220). London: Routledge.

Barkley, R.A. (1997). Behavioral inhibition, sustained attention, and executive functions: Constructing a unifying theory of ADHD. Psychological Bulletin, 121, 65-94.

Belling, P.K., Suss, J., \& Ward, P. (2015). Advancing theory and application of cognitive research in sport: using representative tasks to explain and predict skilld anticipation, decisionmaking, and option-generation behavior. Psychology of Sport 85 Exercise, 16(1), 45-59.

Bernstein, D., Penner, L.A., Clarke-Stewart, A., \& Roy, E. (2011). Psychology (PSY 113 General Psychology) (9th ed.). Belmont, CA, United States: Wadsworth Publishing.

Bossard, C., \& Kermarrec, G. (2011). La prise de décision des joueurs de sports collectifs [Decision-making for team sports players]. Science \& Motricité, 73, 3-22.

Bossard, C., De Keukelaere, C., Cormier, J., Pasco, D., \& Kermarrec, G. (2010). L'activité décisionnelle en phase de contre-attaque en Hockey sur glace [Decision-making during the counter-attack phase in ice hockey]. Activités, 7, 41-61. Retrieved from http://www.activites.org/v7n1/.

Bourbousson, J., R'Kiouak, M., \& Eccles, D.W. (2015). The dynamics of team coordination: A social network analysis as a window to shared awareness. European Journal of Work and Organizational Psychology, 24(5), 742-760.

Bourbousson, J., Poizat, G., Saury, J., \& Sève, C. (2008). Caractérisation des modes de coordination interpersonnelle au sein d'une équipe de basket-ball [Characterization of interpersonal coordination modes within a basket-ball team]. Activités, 1, 21-39.

Cowan, N. (2008). What are the differences between long-term, short-term and working memory? Progress in Brain Research, 169, 323-338.

Dane, S., \& Erzurumluoglu, A. (2003). Sex and handedness differences in eye-hand visual reaction times in handball players. International Journal Neuroscience, 113, 923-929.

De Keukelaere, C., Kermarrec, G., Bossard, C., \& De Loor, P. (2014). Évolution et partage du sentiment de performance collective au cours d'un match de handball [The dynamics and sharedness of perceived collective performance in a highlevel sports team]. Activités, 11, 47-64.

De Keukelaere, C., Kermarrec, G., Bossard, C., Pasco, D., \& Deloor, P. (2013). Formes, contenus et évolution du partage au sein d'une équipe de sport de haut niveau [Sharedness forms, contents and dynamics among expert sport team]. Le Travail Humain, 76(3), 227-255.

Debanne, T., \& Chauvin, C. (2014). Modes of cognitive control in official game handball coaching. Journal of Cognitive Engineering and Decision Making, 8, 283-298.

Debanne, T., Fontayne, P., \& Bourbousson, J. (2014). Professional handball coaches management of players situated understanding during official games. Psychology of Sport and Exercise, 15, 596-604. 
Diamond, A. (2013). Executive functions. Annual Review of Psychology, 64, 135-168.

Endsley, M.R. (1995). Toward a theory of situation awareness in dynamic systems. Human Factors Journal, 37, 32-64.

Endsley, M.R., \& Jones, M. (2001). A model of inter- and intrateam situation awareness: Implications for design, training and measurement. In M. Mc Neese, M. Salas, \& E. Endsley (Eds.), New trends in cooperative activities (pp. 46-47). Santa Monica, CA: Human Factors and Ergonomics Society.

Ericsson, K.A., \& Smith, J. (1991). Prospects and limits of the empirical study of expertise: an introduction. In K. Anders Ericsson \& J. Smith (Eds.), Toward a general theory of expertise: prospects and limits (pp. 1-38). Cambridge, UK: University Press.

Farrow, D., \& Raab, M. (2008). The recipe for expert decision making. In D. Farrow (Ed.), Expertise. AIS.

Fruchart, E., Pâques, P., \& Mullet, E. (2010). Decision-making in basketball and handball games: A developmental perspective. Revue Européenne de Psychologie Appliquée, 60, 27-34.

Furley, P., \& Memmert, D. (2013). "Whom should I pass to?" The more options the more attentional guidance from working memory. PLoS ONE, 8, e62278.

Glockner, A., Heinen, T., Johnson, J.G., \& Raab, M. (2011). Network approaches for expert decisions in sports. Human Movement Science, 31, 318-333.

Gréhaigne, J.-F. (1999). The foundations of tactics and strategy in team sports. Journal of Teaching in Physical Education, 18 (2), 159-174.

Hepler, T.J., \& Feltz, D.L. (2012). Take the first heuristic, selfefficacy, and decision-making in sport. Journal of Experimental Psychology: Applied, 18(2), 154-161.

Hohmann, T., Raab, M., Schlapkohl, N., \& Obeloer, H. (2016). Does training with 3D videos improve decision-making in team invasion sports? Journal of Sport Sciences, 34(8), 746-755.

Johnson, J.G. (2006). Cognitive modeling of decision making in sports. Psychology of Sport and Exercise, 7(6), 631-652.

Johnson, J.G., \& Raab, M. (2003). Take The First: Optiongeneration and resulting choices. Organizational Behavior and Human Decision Processes, 91, 215-229.

Karcher, C., \& Buchheit, M. (2014). On-court demands of elite handball, with special reference to playing positions. Sports Medicine, 44, 797-814.

Kermarrec, G. (2015). Enhancing Tactical Skills in Soccer: Advances from the Naturalistic Decision Making Approach. Procedia Manufacturing, 3(February), 1148-1156.

Kermarrec, G., \& Bossard, C. (2014). Defensive Soccer Players' Decision Making. Journal of Cognitive Engineering and Decision Making, 8(2), 187-199.

Kiss, B., \& Balogh, L. (2019). A study of key cognitive skills in handball using the Vienna test system. Journal of Physical Education and Sport, 19(1), 733-741.

Klein, G.A. (1997). The recognition-primed decision (RPD) model: Looking back, looking forward. In Naturalistic decision making (pp. 285-292). Mahwah, NJ: Lawrence Erlbaum Associates, Inc.

Klein, D.E., Klein, H.A., \& Klein, G.A. (2000). Macrocognition: Linking the cognitive psychology and cognitive ergonomics. In 5th International Conference on Human Interaction with Complex Systems, pp. 173-177.

Kobus, D.A., Proctor, S., \& Holste, S. (2001). Effects of experience and uncertainty during dynamic decision making. Internationl Journal of Industrial Ergonomics, 28(5), 275-290.

Laborde, S., \& Raab, M. (2013). The tale of hearts and reason: the influence of mood on decision making. Journal of Sport $\&$ Exercise Psychology, 35, 339-357.

Lagner, P., Kliegel, M., Phillips, L.H., Ihle, A., Hering, A., Ballhausen, N., \& Schnitzspahn, K.M. (2014). Mood effects on memory and executive control in a real-life situation. Cognition and Emotion, 29(6), 1107-1116.

Lenzen, B., Theunissen, C., \& Cloes, M. (2009). Situated analysis of team handball players' decisions: an exploratory study. Journal of Teaching in Physical Education, 28, 54-74.

Lex, H., Essig, K., Knoblauch, A., \& Schack, T. (2015). Cognitive representations and cognitive processing of teamspecific tactics in soccer. PLoS ONE, 10, 1-18.

Lidor, R., Argov, E., \& Daniel, S. (1998). An exploratory study of perceptual motor abilities of women, novice and skilled players of team handball. Perceptual and Motor Skills, 86, 279-288.

Lyle, J. (2003). Stimulated Recall: A report on its use in naturalistic research. British Educational Research Journal, $29(6), 861-878$.

Macquet, A.-C. (2009). Recognition within the decision-making process: a case study of expert volleyball players. Journal of Applied Sport Psychology, 21, 64-79.

Macquet, A.-C., \& Fleurance, P. (2006). Des modèles théoriques pour étudier l'activité de l'expert en sport - [Theoretical models for studying expert activtiy in sport]. Science $\mathscr{E}$ Motricité, 58(2), 9-41.

Macquet, A.-C., \& Fleurance, P. (2007). Naturalistic decisionmaking in expert badminton players. Ergonomics, 50(9), 14331450 .

Mathieu, J.E., Heffner, T.S., Goodwin, G.F., Salas, E., \& Cannon-Bowers, J.A. (2000). The influence of shared mental models on team process and performance. Journal of Applied Psychology, 85, 273-283.

McMorris, T. (2004). Acquisition and performance of sports skills. Chichester: Wiley: John Wiley \& Sons Ltd.

McMorris, T., \& Beazeley, A. (1997). Performance of experienced and inexperienced soccer players on soccer specific tests of recall, visual search and decision making. Journal of Human Movement Studies, 33, 1-13.

McPherson, S.L., \& Vickers, J.N. (2004). Cognitive control in motor expertise. International Journal of Sport and Exercise Psychology, 2, 274-300.

Memmert, D. (2011). Creativity, expertise, and attention: exploring their development and their relationships. Journal of Sports Sciences, 29, 93-102.

Memmert, D., \& Furley, P. (2007). "I Spy with My Little Eye!": Breadth of Attention, Inattentional Blindness, and Tactical Decision Making in Team Sports. Journal of Sport and Exercise Psychology, 29(3), 365-381.

Memmert, D., Simons, D.J., \& Grimme, T. (2008). The relationship between visual attention and expertise in sports. Psychology of Sport and Exercise, 10, 146-151.

Menevse, A., \& Arslan, C. (2012). Comparison of the correlation between the reaction time and in-game performance of the elite handball teams. Middle-East Journal of Scientific Research, 11, 402-407.

Miyake, A., \& Shah, P. (1999). Models of working memory: mechanisms of active maintenance and executive control. New York: Cambridge University Press.

Moher, D., Liberati, A., Tetzlaff, J., Attman, D.G., \& PRISMA GROUP. (2009). Preferred reporting items for systematic reviews and meta-analyses: the PRISMA Statement. PLoS Med, 6(7), e1000097.

Mouchet, A. (2005). Subjectivity in the articulation between strategy and tactics in team sports: an example in rugby. Italian Journal of Sport Sciences, 12(1), 24-33.

Mouchet, A., \& Bouthier, D. (2006). Prendre en compte la subjectivité des joueurs de rugby pour optimiser l'intervention. [Take into account the subjectivity of rugby players to optimize the intervention.]. Revue STAPS, 72, 93-106.

Phillips, L.H., Bull, R., Adams, E., \& Fraser, L. (2002). Positive mood and executive function: evidence from stroop and fluency tasks. Emotion, 2(1), 12-22. 
Prieto, J., Sampaio, J., \& Gómez, M.-A. (2015). A bibliometric review of the scientific production in handball [Revisão bibliométrica da produção científica no handebol]. Cuadernos de Psicologica Del Deporte, 15(3), 145-154.

Przednowek, K., Sliz, M., Lenik, J., Dziadek, B., Cieszkowski, S., Lenik, P., Kopeć, D., Wardak, K., Przednowek, K. (2019). Psychomotor abilities of professional handball players. International Journal of Environmental Research and Public Health, 16(11), 1909-1920.

Raab, M. (2002). T-ECHO: Model of decision making to explain behaviour in experiments and simulations under time pressure. Psychology of Sport and Exercise, 3, 151-171.

Raab, M., \& Johnson, J.G. (2007). Expertise-based differences in search and option-generation strategies. Journal of Experimental Psychology, 13, 158-170.

Raab, M., \& Laborde, S. (2011). When to blink and when to think: preference for intuitive decisions results in faster and better tactical choices. Research Quarterly for Exercise and Sport, 82, 1-10.

Raab, M., De Oliveira, R.F., \& Heinen, T. (2009). How do people perceive and generate options? How do people perceive and generate options? Progress in Brain Research, 174, 49-59.

Reynolds, S. (2015). Fire up your writing brain: how to use proven neuroscience to become a more creative, productive, and successful writer. Cincinnati, Ohio: Writer's Digest.

Robinson, P.E. (2014). Foundation of sports coaching (2nd ed.). New York: Routledge.

Rousanoglou, E.N., Noutsos, K.S., Bayios, I.A., \& Boudolos, K. D. (2015). Self-paced and temporally constrained throwing performance by team- handball experts and novices without foreknowledge of target position. Journal of Sports Science and Medicine, 14, 41-46.

Royal, K.A., Farrow, D., Mujika, I., Halson, S.L., Pyne, D., \& Abernethy, B. (2006). The effects of fatigue on decision making and shooting skill performance in water polo players. Journal of Sports Sciences, 24(8), 807-815.

Rulence-Pâques, P., Fruchart, E., Dru, V., \& Mullet, E. (2005). Cognitive algebra in sport decision-making. Theory and Decision, 58, 387-406.

Salthouse, T.A. (2005). Relations between cognitive abilities and measures of executive functioning. Neuropsychology, 19, 532545.

Saury, J., Durand, M., \& Theureau, J. (1997). L'action d'un entraîneur expert en voile en situation de compétition: étude de cas. Contribution à une analyse ergonomique de l'entraînement. Science \& Motricité, 31, 21-35.

Savelsbergh, G.J.P., Williams, A.M., Van der Kamp, J., \& Ward, P. (2002). Visual search, anticipation and expertise in soccer goalkeepers. Journal of Sports Sciences, 20(3), 279-287.

Schack, T., \& Mechsner, F. (2006). Representation of motor skills in human long-term memory. NeuroScience Letters, 391 (1), $77-81$.

Schapschröer, M., Baker, J., \& Schorer, J. (2016a). Effects of domain-specific exercise load on speed and accuracy of a domain-specific perceptual-cognitive task. Human Movement Science, 48, 121-131.

Schapschröer, M., Baker, J., \& Schorer, J. (2016b). Exploring the interaction of physical exercise load and pattern recall performance in female handball players. Experimental Brain Research, 234, 1713-1723.
Sève, C., Bourbousson, J., Poizat, G., \& Saury, J. (2009). Cognition et performance collectives en sport [Cognition and collective performance in sport]. Intellectica, 52(2), 1-25.

Souchon, N., Cabagno, G., Traclet, A., Trouilloud, D., \& Maio, G. (2009). Referees' use of heuristics: the moderating impact of standard of competition. Journal of Sports Sciences, $27(7)$, 695-700.

Suchman, L. (1987). Plans and situated action. New York: Cambridge University Press.

Swann, C., Moran, A., \& Piggott, D. (2015). Defining elite athletes: Issues in the study of expert performance in sport psychology. Psychology of Sport and Exercise, 16(1), 3-14.

Szczypinska, M., \& Mikicin, M. (2019). Original article does attention training induce any changes in the level of the selected cognitive processes in handball players. Journal of Physical Education and Sport, 19(4), 1445-1452.

Tenenbaum, G., \& Bar-Eli, M. (1993). Decision making in sport: a cognitive perspective. In M. Murphey, L.K. Tennant, \& R.N. Singer (Eds.), Handbook of research on sport psychology (pp. 171-192). New York: Macmillan Publishing Co. Inc.

Tenenbaum, G., Kolker, N.L., Bar-Eli, M., \& Weinberg, R. (1994). Information recall of younger and older skilled athletes: The role of display complexity, attentional resources and visual exposure duration. Journal of Sport Sciences, 12, 529-534.

Tenenbaum, G., Yuval, R., Elbaz, G., Bar-Eli, M., \& Weinberg, R. (1993). The relationship between cognitive characteristics and decision making. Canadian Journal of Applied Physiology, $18,48-62$.

Theureau, J. (1992). Le cours d'action: analyse sémiologique. Essai d'une anthropologie cognitivie située. Berne: Peter Lang.

Theureau, J. (2006). Le cours d'action: Méthode développée [Course of action: developped method]. Toulouse: Octares.

Verburgh, L., Scherder, E.J.A., Van Lange, P.A.M., \& Oosterlaan, J. (2014). Executive functioning in highly talented soccer players. PLoS ONE, 9(3), e91254.

Vermersch, P. (2018). The explicitation interview. French original ESF 1994.

Wagner, H., Finkenzeller, T., Würth, S., \& Von Duvillard, S.P. (2014). Individual and team performance in team-handball: a review. Journal of Sports Science and Medicine, 13, 808-816.

Weigel, P., Raab, M., \& Wollny, R. (2015). Tactical Decision Making in Team Sports - A Model of Cognitive Processes. International Journal of Sports Science, 5(4), 128-138.

Williams, A.M., \& Ford, P.R. (2008). Expertise and expert performance in sport. International Review of Sport and Exercise Psychology, 1(1), 4-18.

Williams, A.M., \& Ward, P. (2007). Anticipation and decision making: exploring new horizons. In G.T. \& R. Eklund (Eds.), Sport Expertise (pp. 203-223).

Williams, A.M., Davids, K., \& Williams, J.G. (1999). Visual Perception \& Action in Sport (E. Spon, Ed.). London-New York: Taylos \& Francis.

Williams, A.M., Janelle, C.M., \& Davids, K. (2004). Constraints on the search for visual information in sport. International Journal of Sport and Exercise Psychology, 2, 301-318.

Zwierko, T. (2007). Differences in peripheral perception between athletes and nonathletes. Journal of Human Kinetics, 19, 53-62.

Cite this article as: Bonnet G, Debanne T, \& Laffaye G (2020) Toward a better theoretical and practical understanding of field players' decision-making in handball: A systematic review. Mov Sport Sci/Sci Mot, 110, 1-19 